\title{
Implications of Intellectual Property Rights for Dynamic Gains from Trade
}

\author{
Michele Connolly \\ Duke University \\ and \\ Diego Valderrama \\ Federal Reserve Bank of San Francisco
}

Working Paper 2004-23

http://www.frbsf.org/publications/economics/papers/2004/wp04-23bk.pdf

The views in this paper are solely the responsibility of the authors and should not be interpreted as reflecting the views of the Federal Reserve Bank of San Francisco or the Board of Governors of the Federal Reserve System. 


\title{
Implications of Intellectual Property Rights for
}

\author{
Dynamic Gains from Trade ${ }^{1}$
}

Michelle Connolly ${ }^{2}$

Duke University
Diego Valderrama ${ }^{3}$

Federal Reserve Bank of San Francisco

July 11, 2005

\footnotetext{
${ }^{1}$ The views expressed herein are those of the authors and do not necessarily reflect those of the Federal Reserve Bank of San Francisco or the Federal Reserve System. We thank Robert Evenson, Enrique Mendoza, Robert Mundell, Pietro Peretto, Xavier Sala-i-Martin, T.N. Srinivasan, and Kei-Mu Yi for helpful comments and Gregory Snyders for excellent research assistance.

${ }^{2}$ Department of Economics, 305 Social Sciences, Box 90097, Durham, NC 27708-0087, USA. Email: connolly@econ.duke.edu

${ }^{3}$ Economic Research, 101 Market Street, MS 1130, San Francisco, CA 94105, USA. Telephone: +1 (415) 974-3225. Facsimile: +1 (415) 974-2168. Email: Diego.Valderrama@sf.frb.org.
} 


\begin{abstract}
A simple intellectual property rights (IPRs) framework is introduced into a dynamic quality ladder model of technological diffusion between innovating firms in one country and imitating firms in another country. The presence of technological spillovers and feedback effects between firms in the two countries demonstrates that, even when steady state growth increases, transition costs sometimes dominate steady state welfare gains. Most existing models of international IPRs find that high intellectual property enforcement in the imitating country leads to welfare gains in the innovating country at the expense of the imitating country. In contrast, we find IPR regimes that, even after accounting for transition costs, positively affect welfare in both countries. Preferred IPR regimes maintain competition from imitative activity but enforce some remuneration to innovators for the spillovers they generate. Welldesigned IPR regimes imposed at the time of trade liberalization will be welfare enhancing for both regions relative to trade liberalization without IPR enforcement.

JEL Codes: F1, F43, O31, O34, O40
\end{abstract}

Key Words: Intellectual Property Rights, Technological Diffusion, International Trade. 
It is traditionally argued that the enforcement of intellectual property rights (IPRs) is necessary to compensate innovators for incurring the fixed costs of research and development (R\&D). The argument in support of finite domestic patent protection is familiar. On one hand, patents provide monopoly rights to innovators as an incentive to innovate. On the other hand, once the innovation has occurred it is socially optimal (in a one-time game) for the government to revoke patent protection so as to lower the price of the invention and increase its use. In a repeated game, however, such a policy would severely dampen future innovations. Hence, the government legally maintains monopoly rights for innovators, but only for a finite time. A similar trade-off exists between developed countries, where a majority of innovations occur, and developing countries that wish to have greater access to these innovations through lower prices. Developed countries have therefore pushed for international enforcement of IPRs, while developing countries believe that international enforcement will slow technological acquisition and development. The promotion of Trade Related Aspects of Intellectual Property Rights (TRIPS) by the World Trade Organization highlights the perceived importance of enforcing IPRs as developing countries liberalize trade.

It is commonly assumed that developed countries will always find it optimal to have full international IPRs and that developing countries will always find it optimal to have no IPR enforcement. Recent work by Gene Grossman and Edwin Lai (2004) considers a NorthSouth environment where both countries have innovating firms, although the North has a greater capacity for innovation. They consider globally efficient regimes of patent protection within a variety-expanding model. In that environment, among policy combinations that give the same overall incentives for global innovation, the stronger the patent protection in the South, the greater the gain for the North at the expense of the South.

Here we introduce IPRs into a North-South model of technological diffusion through trade and imitation. The model explicitly considers positive spillovers from innovation in the North to imitative research in the South through exposure to trade. These spillovers, 
in combination with feedback effects between innovating Northern and imitating Southern firms, implies that welfare in both regions depends on how IPRs affect world growth. Rather than finding that increasing IPR protection in the South always increases Northern welfare at the expense of the South, we find that properly designed Southern IPRs are welfare enhancing for both regions, especially during Southern trade liberalization. Similarly, poorly designed IPRs are welfare decreasing for both regions. Our results do not necessarily imply that both regions' welfare will be maximized by exactly the same level of IPR protection. But it does mean that IPRs don't always favor developed nations at the expense of developing nations.

This paper gives important insights into the value of internationally enforced IPRs from the perspective of both developing and developed nations. Importantly, we provide numerical evaluations of dynamic growth effects in both transition and steady-state that have not been considered in the existing literature on IPRs. Here we present only the salient features of the model and focus on its results. (See Michelle Connolly and Diego Valderrama (2005a) for further details about the model and its solution.)

\section{The Model}

Consider two regions. The North represents innovating economies and the South represents currently non-innovating economies. We introduce IPRs into an existing model of technological diffusion through reverse-engineering of technology embodied in intermediate goods by Connolly and Valderrama (2005b). International trade with reverse engineering of intermediate goods leads to feedback effects between Northern innovators and Southern imitators who compete for the Southern market. Consequently, both regions face transition paths dependent on their relative technologies.

Consider a very simple IPR environment. There are full IPRs in the North, so domestic sales by Northern innovating firms are only dislodged by future domestic innovations. However, Northern sales in the South can be wiped out by future Northern innovation or by 
Southern imitation. Consider two possible IPR regimes in the South. In the first regime, a Southern firm must compensate, through a licensing fee, the Northern firm it has imitated to be allowed to sell domestically. Without IPR enforcement, that transfer is zero. As IPR enforcement rises, so does the licensing payment. In the second regime, in a similar vein as Elhanan Helpman (1993), IPR enforcement affects the ability to sell an imitated good; i.e. a Southern imitator will be able to sell with probability $p_{C}\left(1-p_{I P R}\right)$, where $p_{C}$ is the probability of imitation (copying) and $p_{I P R}$ is the probability of IPR enforcement.

We assume balanced trade and no international capital flows. The domestic interest rate is therefore determined by domestic technology. With trade, firms can use imports of intermediate goods in final goods production. Southern firms import all intermediate goods that have not yet been copied, and export the Southern final good. Since the South can immediately import higher quality Northern intermediate goods for use in final goods production, it is not limited by its own technology. This implies that, with sufficiently low trade barriers, Southern output growth is determined by Northern technological progress.

A representative household in country $i$ maximizes the present value of lifetime utility,

$$
\max _{\left\{C_{i}, C_{i}^{*}, v\right\}_{t \rightarrow \infty}} \int_{0}^{\infty} u\left(C_{i}\right) e^{-\rho t} d t .
$$

$C_{i}$ is a Cobb-Douglas aggregator of domestic and imported final goods. We assume that both countries spend equal proportions on each type of final good. The change in domestic assets is given by the difference in labor and interest income minus final consumption expenditures. Household demand for each good depends only on its relative price and expenditure levels. Optimal control techniques yield consumption growth,

$$
\frac{\dot{C}_{i}}{C_{i}}=\frac{1}{\theta}\left(r_{i}-\frac{\dot{\bar{P}}_{i}}{\bar{P}_{i}}-\rho\right),
$$


where $\frac{1}{\theta}$ is the constant intertemporal elasticity of substitution, $r_{i}$ is the domestic interest rate and $\bar{P}_{i}$ is the consumption-based price index.

On the production side, we begin with a standard quality ladder model (Robert Barro and Xavier Sala-i-Martin 1997). There are a fixed number, J, of intermediate sectors. With limit pricing, only the highest quality good is sold in each sector. The quality of each good increases with successful innovations. Each quality improvement can be thought of as stepping one rung further up a ladder. The size of each step reflects the size of quality improvements. We set the size of this step to be a constant, $q$, greater than 1 . The rung at which the good is located on the ladder is denoted by $k$. Normalizing so all goods begin at quality level 1 , the quality of an intermediate good in sector $j$ will rise from 1 to $q$ with the first innovation, to $q^{2}$ with the second innovation, and to $q^{k_{j}}$ with the $k_{j}$ th innovation.

Since technology is embodied in intermediate goods, output growth in each country is driven by technological advances in the quality of domestically available inputs, regardless of country of origin. Aggregate final goods production is undertaken by many perfectly competitive firms in the North $(N)$ and the South $(S)$ :

$$
Y_{i}=A_{i} L_{i}^{\alpha} \sum_{j=1}^{J}\left(q^{k_{N_{j}}} \hat{x}_{i k_{j}}\right)^{1-\alpha}, i \in\{N, S\}
$$

$A$ is a productivity parameter dependent upon domestic institutions. $L$ is the labor input used in final goods production, and $q^{k_{N_{j}}} \hat{x}_{i k_{j}}$ is the quality-adjusted level of intermediate good $j$ used in final goods production. This intermediate good can be domestic or foreign produced. Each country produces a different final good that can be used in research and can be costlessly transformed into intermediate goods. Let the Northern final good, $Y_{N}$ be the numeraire, so $P_{N}=1$. The Southern final good, $Y_{S}$, has price $P_{S}$.

Which country actually produces a particular intermediate good depends on each country's technological level, as well as trade barriers and IPR enforcement. By assumption, the 
North is the more technologically advanced country. Therefore, it must innovate to push forward its (and the world's) technology. The South increases its domestic technology by imitating Northern technology, at least until the technology gap is eliminated.

Once knowledge of how to produce an intermediate good exists domestically, it can be produced using the final goods production function. Hence, the marginal cost of producing an intermediate good equals the marginal cost, $M C_{i}$, of producing the final good. So the marginal cost of producing an intermediate good is independent of its quality and is identical across all domestic sectors. We parameterize the model to yield higher Northern marginal costs to enable successful imitating firms to underprice Northern competitors.

The lead innovating firm in each sector uses limit pricing to wipe out sales of lower quality goods. Innovations are drastic; for given Southern tariffs on intermediates, $\tau_{x_{S}}$, and $M C_{S}$, the size of quality improvements is large enough for a Northern firm to hold the world market with a single quality level improvement over a Southern copy (i.e. $\left.q>\left[\left(1+\tau_{x_{S}}\right) / M C_{S}\right]\right)$.

With monopolistic competition in the intermediate sector, expected profits depend on the closest competition faced by the firm. In the North, full IPR enforcement guarantees that Northern innovators always face the previous Northern innovator as their closest competitor. Assuming $q(1-\alpha) \leq 1$, they will choose a limit price slightly below $q M C_{N}=q$. Since the latest innovation is $q$ times more productive than its predecessor and since $M C_{N}=1, q$ is the lowest price at which the previous innovator could sell without earning negative profits. This limit price will wipe out Northern sales of all older technologies.

In the Southern market there are three types of firms: Northern exporting firms facing Northern competition, $n_{N N}^{*}$, Northern exporting firms facing Southern competition, $n_{N S}^{*}$, and Southern imitating firms facing Northern competition, $n_{S}$. Since there are $J$ sectors, $J=n_{S}+n_{N S}^{*}+n_{N N}^{*}$. They will respectively have limit prices: $P_{N N}^{*}=q\left(1+\tau_{x_{S}}+t\right)$, $P_{N S}^{*}=q M C_{S}$, and $P_{S}=1+\tau_{x_{S}}+t$.

In either country $i$, for a given limit price, $P_{x_{i j}}$, and final goods price, $P_{i}$, implied demand 
for intermediate goods in sector $j$ is

$$
x_{i j}=L_{i}\left[A_{i}(1-\alpha) q^{k_{i j}(1-\alpha)} \frac{P_{i}}{P_{x_{i j}}}\right]^{\frac{1}{\alpha}} .
$$

Firms choose the resources to devote to research based on the expected present value of profits for successful research, which depends on the probabilities of innovation and imitation. Within an intermediate goods sector $j$, presently at quality level $k_{N j}, p_{I k_{N j}}$ is the probability per unit of time that the next innovation occurs. $p_{I k_{N j}}$ follows a Poisson process, which depends positively on resources devoted to research, $z_{I k_{N j}}$, and past industry specific domestic learning-to-learn, $\vartheta_{k_{N j}}$, and negatively on the complexity, $\varphi_{I k_{N j}}$, of the good upon which firms are attempting to improve:

$$
\begin{aligned}
p_{I k_{N j}} & =z_{I k_{N j}} \vartheta_{k_{N j}} \varphi_{I k_{N j}}, \text { where } \\
\vartheta_{k_{N j}} & =\beta_{I} q^{k_{N j}}, \text { and } \varphi_{I k_{N j}}=\frac{1}{\zeta_{I}} q^{\frac{-k_{N j}}{\alpha}} .
\end{aligned}
$$

$\beta_{I}$ reflects a positive spillover from past experience, while $\zeta_{I}$ is a fixed cost of innovative research. The probability, $p_{C k_{N j}}$, of imitating the current technology, $k_{N j}$, is

$$
\begin{aligned}
p_{C k_{N j}} & =z_{C k_{N j}} \vartheta_{k_{S j}} \varphi_{I k_{N j}}, \text { where } \\
\vartheta_{k_{S j}} & =\beta_{C} q^{k_{S j}}, \varphi_{C k_{N j}}=\frac{e^{\omega}}{\zeta_{C} \hat{q}_{j}^{\sigma}} q^{\frac{-k_{N j}}{\alpha}}, \sigma>1, \\
\hat{q}_{j} & =\frac{q^{k_{S j}}}{q^{k_{N j}}}, \omega=\left(\frac{M}{Q_{N}}\right)^{\eta}, \text { and } Q_{N}=\sum_{j=1}^{J} q^{\frac{k_{N j}(1-\alpha)}{\alpha}} .
\end{aligned}
$$

Learning in the South depends on the highest sector-specific experience gained through imitation. The spillover from innovative experience, $\beta_{I}$, is greater than that from imitation, $\beta_{C}$. Relative to innovation, two new factors affect imitation. First, the cost of imitation depends positively on the sector $j$ South/North technology ratio, $\hat{q}_{j}$, reflecting the increasing 
cost of imitation as the pool of goods to be imitated diminishes. Second, $e^{\omega}$ reflects lower costs of gathering information about foreign goods with greater interaction, $\omega$, between the two countries, as measured by Southern imports of intermediate goods, $M$, scaled by the aggregate Northern technology level, $Q_{N}$. Since the cost of imitation increases as the technology gap decreases, $p_{C}$, and consequently $p_{I}$, change in transition to steady-state.

A Northern firm loses its profits from sales to the Northern market when the next innovation occurs. It loses its expected Southern profits when it is imitated by a Southern firm or when the next innovation occurs. A Southern firm loses its profits when the next innovation occurs. Free entry into innovative and imitative research guarantees that research costs $\left(Z_{I}\right.$ and $Z_{C}$, respectively) will exactly equal the expected present discounted value of profits.

Entry and exit into $n_{S}, n_{N S}^{*}$, and $n_{N N}^{*}$ depend on $p_{I P R}$ and the average $p_{C}$ and $p_{I}$ :

$$
\begin{aligned}
\dot{n}_{N N}^{*} & =p_{I}\left(1-p_{C}\right) n_{N S}^{*}-\left[p_{I} p_{C}+\left(1-p_{I}\right)\left(1-p_{I P R}\right) p_{C}\right] n_{N N}^{*} \\
\dot{n}_{N S}^{*} & =p_{I}\left(p_{C} n_{N N}^{*}+n_{S}\right)-\left[\left(1-p_{I}\right)\left(1-p_{I P R}\right) p_{C}+p_{I}\left(1-p_{C}\right)\right] n_{N S}^{*} \\
\dot{n}_{S} & =\left(1-p_{I}\right)\left(1-p_{I P R}\right) p_{C}\left(n_{N N}^{*}+n_{N S}^{*}\right)-p_{I} n_{S} .
\end{aligned}
$$

Note that in our first IPR scenario, $p_{I P R}=0$.

Finally, there are two world resource constraints

$$
\begin{aligned}
Y_{N} & =C_{N}+X_{N}+Z_{N}+C_{N}^{*}+n_{N S}^{*} X_{N S}^{*}+n_{N N}^{*} X_{N N}^{*} \\
Y_{S} & =C_{S}+n_{S} X_{S}+Z_{S}+C_{S}^{*},
\end{aligned}
$$

where $Z_{i}$ represents aggregate research costs and $X$ represents intermediate goods in different categories.

Solutions are found using the free entry conditions, sector category expressions, two world resource constraints, a balanced trade condition, two consumer demand conditions, 
two consumption growth conditions, and the functional forms for $p_{I}$ and $p_{C}$.

\section{Results}

First consider trade liberalization in the South, independently of any Southern IPRs. Lowering Southern tariffs causes a large initial increase in imitation, which then falls in transition but remains above its previous steady-state level. Innovation drops slightly on impact, but then rises gradually until it reaches a new higher steady-state level equal to that of imitation. This leads to higher world growth. In steady-state, this is welfare-enhancing for both countries. However, there are transition costs, borne principally by the North. The transitional welfare loss outweighs the North's steady-state welfare gain. In the next experiments we see that this welfare loss is due to a lack of internationally enforced IPRs rather than Southern trade liberalization per se.

Consider the two possible IPR regimes mentioned above. In the first, imitation is allowed to continue, but imitators are forced to partially remunerate the Northern innovators they have imitated. For simplicity we simulate this by considering a one time licensing fee from the Southern imitator to the innovator. This raises the fixed cost of imitation and offsets some of the fixed costs of innovation. Liberalizing Southern trade in combination with this fee leads to a jump in innovation and a fall in imitation on impact. In transition the innovation slows but remains at a higher steady-state level. Imitation gradually increases until it equals the rate of innovation. This regime yields faster rates of innovation and growth than with Southern trade liberalization alone. This is due to the presence of spillovers from Northern innovation to Southern imitative research through exposure to the Northern technology embodied in imported intermediates. As IPR enforcement increases in the South, this spillover is partially internalized since the Northern firms are receiving some remuneration for this externality. Hence, the rate of innovation increases more than in the case of trade liberalization without concurrent increases in Southern IPRs. Welfare (including the 
transition) increases unambiguously for both the North and the South. Moreover, because of this added boost to technological progress, Southern welfare increases by more than if it had liberalized without accepting this licensing arrangement.

In the second IPR regime, the Southern government raises $p_{I P R}$ at the same time as it lowers tariffs. In this case, Northern firms effectively face less competition from Southern imitators, causing them to slow their rate of innovation. Hence, imposing IPRs that limit competition from the South end up being welfare reducing for both regions. ${ }^{1}$

Comparing these two IPR regimes in the context of trade liberalization for a developing region highlights four important points. First, the welfare implications for IPR strengthening in developing countries differ greatly depending on the design of the IPR regime. Second, the optimal IPR regime depends on whether or not technological diffusion is occurring and whether or not there are feedback effects between innovating firms and imitating firms. Third, it is important to consider not only steady-state results, but also the transition paths when determining welfare effects. Finally, the presence of feedback effects suggests that, unlike most previous findings, there may not be a direct conflict on optimal IPR design from the perspective of developed and developing nations. Namely, in a model of technological diffusion, both regions ultimately care about the same world growth rate. Hence, IPR policies that maximize this world growth rate will be in the interest of both regions. 


\section{References}

[1] Barro, Robert and Sala-i-Martin, Xavier. "Technological Diffusion, Convergence, and Growth." Journal of Economic Growth. March 1997, 2(1), pp. 1-26.

[2] Connolly, Michelle and Valderrama, Diego. "Intellectual Property Rights Design and Dynamic Gains from Trade.” Mimeo, 2005a.

[3] __-_. "North-South Technological Diffusion and Dynamic Gains from Trade." Mimeo, 2005b.

[4] Grossman, Gene and Lai, Edwin L.-C. "International Protection of Intellectual Property." American Economic Review. December 2004, $94(5)$.

[5] Helpman, Elhanan. "Innovation, Imitation, and Intellectual Property Rights." Econometrica, November 1993, 61(6), 1247-1280. 


\section{Notes}

${ }^{1}$ This is in line with Helpman's (1993) findings that higher IPRs decreased the rate of imitation in a dynamic North-South model. 